\title{
LOS HIMNOS HOMÉRICOS CORTOS Y LAS PLEGARIAS CULTUALES *
}

Traditionally, the attempt to determine the function of the shorter Homeric hymns and to adscribe them to a precise literary genre was accomplished mostly through internal analysis and the examination of the secondary sources. In this paper I will try to argue for the need to compare these poems with other literary manifestations exhibiting comparable elements. This way, we are immediately led to noticing the similarities between the above and the genre of the cultual prayers and the archaic proemia. Once I have established: a) the relation between the short Hymns and the prayers, and b) the proemiatic character that can be assigned to at least some of these Hymns, I will try to determine the occasion on which they were performed and, in the case of the proemiatic Hymns, what kind of work or performance they would introduce. Finally, the theogonic nature of these Hymns will be briefly discussed.

Entre los numerosos problemas que plantean los himnos homéricos vamos a centrarnos en este artículo en la cuestión del género literario al que pertenecen, que fue el principal motivo de preocupación de sus estudiosos en toda una larga primera etapa, hasta que a finales de los años setenta el interés por la concepción religiosa que manifiestan, partiendo sobre todo del análisis de los himnos largos, pasó a primer plano en la crítica. Ello fue debido en gran parte a un cierto escepticismo respecto a las conclusiones a que se había llegado sobre el género literario al que pertenecen, que es el tema que pretendemos volver a suscitar, y a la falta de propuestas alternativas.

La dificultad principal que plantea el estudio de los himnos radica en entender la función de estas piezas y la ocasión en que se ejecutaban. Desde F.A. Wolf en sus Prolegomena ad Homerum de 1795 la mayor parte de los estudiosos mantienen que los himnos eran proemios que precedían a una ejecución rapsódica de cantos épicos, aunque con reservas por parte de muchos respecto a los himnos largos. Las propuestas principales derivan de esa misma idea,

* Agradezco sus observaciones a D. Alberto Bernabé y D. Javier de Hoz. 
como por ej. la de F. Càssola de que algunos himnos cortos parecen exordios de los himnos largos, y los demás pueden considerarse exordios de himnos largos perdidos, o incluso marcos para introducir y concluir una narración mítica más larga sobre el dios. Los himnos largos serían entonces los verdaderos proemios, que tendrían su lugar como primera rapsodia de una larga serie, posiblemente en un contexto agonal ${ }^{1}$.

Aunque haremos frecuentes alusiones a los himnos largos, e incluiremos elementos de éstos en el análisis de los diferentes aspectos, vamos a centrar este estudio en los himnos cortos, con el fin de establecer la función y el género al que éstos pueden adscribirse. Si bien vamos a ver que los himnos largos son probablemente una expansión de los breves, y que por eso presentan numerosos elementos comunes a éstos, hay que tener en cuenta que la colección de himnos es homogénea sólo desde un punto de vista formal, no funcional. En general, el estudio del género se ha realizado principalmente mediante el análisis interno y el de las escasas fuentes secundarias sobre ellos. Existe sin embargo otra fuente fundamental para cualquier estudio de género, que es la formada por otros testimonios, preferentemente de la misma época, que muestran un contenido similar y cuya función pudiera ser la misma. En este caso se trata de estudiar la posible relación de los himnos cortos con la plegaria y el proemio arcaicos, aunque sin dejar de tratar las otras dos fuentes señaladas, de las cuales sobre todo el análisis interno es imprescindible para poder pasar a la comparación con otros testimonios.

\section{Análisis interno}

Todas las piezas de la colección tienen una serie de rasgos y elementos comunes que justifican su agrupación. Algunos de ellos son propios de la épica: la composición hexamétrica, el estilo formulario y la invocación a la musa en algunos himnos para que inspire el canto. Pero otros son rasgos claramente líricos: su estructura triádica, con una introducción, una parte central, y una conclusión de carácter personal, y el que en muchos de ellos el aedo cante en primera persona como autor. El contenido del núcleo central, que es una narración de gestas divinas o una descripción de los atributos o timai del dios, lo encontramos frecuentemente en piezas líricas, sobre todo corales, pero también en la épica de tipo didáctico o gnómico. Tenemos pues unos cantos pertenecientes a un género que no se puede calificar con toda propiedad ni de lírico ni de épico. En realidad, esto es lo que ocurre con las obras de otros autores arcaicos, por ejemplo de Estesícoro, y apoya la demos-

1 F. Càssola, Inni Omerici, Milán 1975, pp. XII-XXI. 
tración de B. Gentili de que las diferencias principales entre distintas formas líricas, y entre lírica y épica se encuentran no tanto en el contenido o la forma, como en la ejecución, que es donde se entrecruzan las competencias del poeta y el público, es decir en la ocasión y la función del canto ${ }^{2}$.

Analicemos las distintas partes de esta estructura tripartita, en la que la introducción y la conclusión juegan con un número limitado de elementos.

a) En la introducción aparece el teónimo en acusativo (a veces con la prep. ŏ $\mu \varphi$, por ej. en XXII) y lo más cerca posible del comienzo, uno o varios atributos

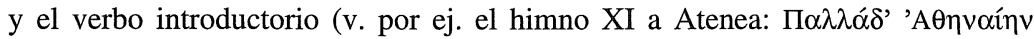

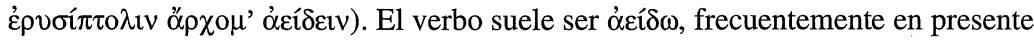
y primera persona, pero atestiguado también en futuro: ớo $\mu \alpha \mathrm{r}$ (VI, X, XV, $\mathrm{XXX}$ ), y a veces sustituído por la perífrasis ő $\rho \chi \mu^{\prime}$ ' $\alpha \varepsilon i ́ \delta \varepsilon \imath v$ (II, XI, XIII, XVI, XXVI, XXVIII) que tiene su importancia como luego veremos. Otras variantes

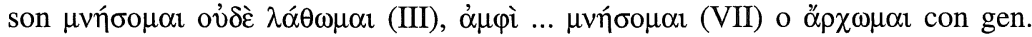
del o los teónimos (XXV). En todos estos casos es el aedo el que canta y lo anuncia utilizando la primera persona. Pero hay también algunos himnos en los que el aedo le pide a la Musa (a menudo llamada $\lambda i ́ \gamma \varepsilon 1 \alpha$ ) que cante o que le inspire, de la forma bien conocida en la épica: vँ $\mu v \varepsilon t$ Moṽ $\sigma \alpha$ (IV, IX,

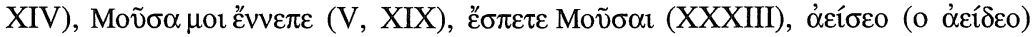
Moṽ $\sigma \alpha(X V I I, X X)$. El himno V a Afrodita es el único en el que el objeto del canto no es la divinidad sino sus ép $\alpha$ (cf. el exordio de la Odisea). Aparte de estas pequeñas variantes, en lo que más pueden diferenciarse unas introducciones de otras es en la mayor o menor extensión de los atributos del dios. Los que más se apartan de esta introducción son los himnos XXI a Apolo y XXIV y XXIX a Hestia, que se inician con el vocativo del teónimo y se dirigen al dios en segunda persona. En el de Apolo el aedo introduce una variante: «a tí te canta el cisne...», pero añade a continuación una frase formularia: «a tí te canta el aedo el primero y el último».

b) La parte central es la más extensa y la que contiene la conmemoración del dios. Se suele distinguir entre aquellas partes que se centran en el relato de las hazañas del dios, a las que se suele dar el nombre de míticas, y aquellas que constituyen una descripción de las funciones, esferas de actividad, epifanías y atributos divinos en general, de donde el nombre de atributiva o descriptiva ${ }^{3}$. El contenido más frecuente del núcleo central de los himnos cortos es la descripción, poco desarrollada, de alguno o varios aspectos de la divinidad: sus padres y lugar de nacimiento, sus timai, su apariencia, sus facetas, sus poderes en el Olimpo y hacia los mortales, alguna costumbre o acción frecuente en la vida del dios. El

2 B. Gentili, «Lirica greca arcaica e tardo arcaica», en Introduzione allo studio della cultura classica, Milán, 1972, pp. 57-105. Sobre la mezcla de elementos épicos y líricos en Estesícoro, y sobre la ocasión de ejecución de sus obras en relación con los peanes en fiestas populares, v. E. Cingano, «Indizi di esecuzione corale in Stesicoro», en R. Pretagostini (ed.), Tradizione e innovazione nella cultura greca da Omero all'età ellenistica, Roma, 1993, pp. 347-61.

3 v. R. Janko, «The structure of the Homeric Hymns. A study in genre», Hermes 109, 1981, p. 11. 
tiempo verbal empleado en estas aretalogías es el presente, excepto cuando al comienzo se narra brevemente en pasado el nacimiento, y a veces la admisión del dios en el Olimpo. Es fundamental hacer aquí una precisión que no suele hacerse al analizar esta parte, y es su orientación a la relación de la divinidad con los mortales, o a su relación con el Olimpo y los otros dioses. Por ejemplo en los himnos XXV a las Musas, Apolo y Zeus, XXIX a Hestia y Hermes y XXX a Ge, la parte central está dedicada exclusivamente a los beneficios que estos dioses otorgan a los mortales, lo mismo que en el himno XXXIII a los dioscuros, aunque en este caso un breve relato del nacimiento de los dioses precede a sus timai. El XX se centra en las enseñanzas, en pasado, de HEfesto a los hombres, y el VII, también en pasado, en una epifanía de Dioniso. Otros himnos están dedicados a la relación del dios con el Olimpo, normalmente mediante la narración de momentos pasados: el VI a la llegada de Afrodita al Olimpo; el XV al nacimiento, gestas y llegada al Olimpo de Heracles; el XVII, XVIII y XXVIII al nacimiento de los Dioscuros, Hermes y Atenea; el XXVI a la crianza de Dioniso. De estructura más compleja son los himnos XIX a Pan y XXVII a Ártemis, de tipo atributivo, pero en los que se describe la costumbre del dios de dirigir los coros, poniéndose así, en boca de éstos, el relato mítico del nacimiento. Únicamente los himnos XIII a Démeter y XXI a Apolo carecen de parte central.

Normalmente el elemento de unión entre la introducción y esta segunda parte

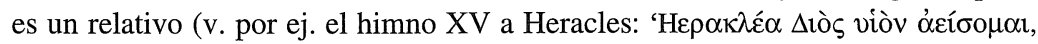

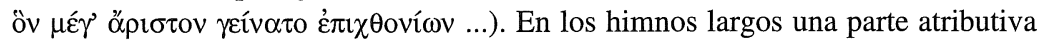
corta suele preceder a una larga narración mítica bien sea sobre el nacimiento del dios, como en los himnos a Apolo y Hermes, bien sobre algún episodio mítico de su vida, también en relación con sus poderes y atribuciones como en el himno a Afrodita y a Démeter.

c) La conclusión tiene alguno de o los tres siguientes elementos: saludo, petición y una expresión del deseo de agradar al dios bien sea mediante el himno en cuestión, bien mediante la promesa de un futuro canto.

Las fórmulas de saludo son las siguientes:

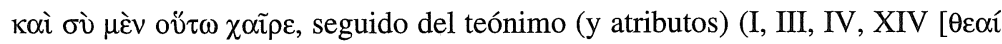

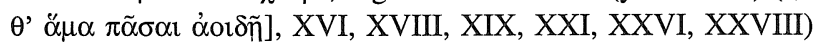

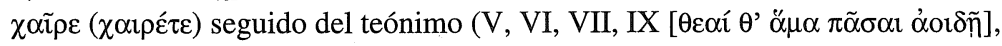
$\mathrm{X}, \mathrm{XI}, \mathrm{XIII}, \mathrm{XV}, \mathrm{XVII}, \mathrm{XVIII}$; XXII, XXV, XXVII, XXIX, XXX, XXXIII)

En estas fórmulas considero que hay que interpretar el verbo $\chi \alpha$ ĩ hace W.H. Race, en su doble sentido como expresión a la vez de saludo y del deseo de complacer al dios ${ }^{4}$. Este segundo sentido se refleja más claramente en

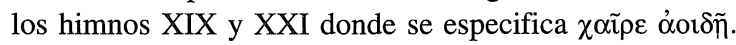

Las fórmulas de petición pueden referirse al propio canto, pero también ser de carácter general.

Peticiones referidas al canto:

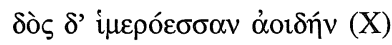

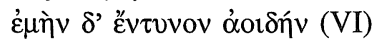

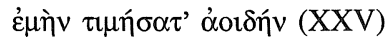

4 W.H. Race, «Aspects of Rhetoric and Form in Greek Hymns», GRBS 23, 1982, pp. 8-10. 


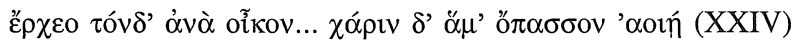

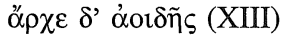

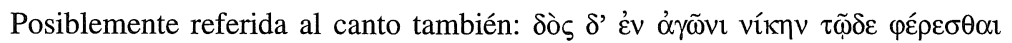
(VI), fórmula especialmente interesante para la interpretación de las posibles ocasiones en que se presentaban estos cantos.

Peticiones de carácter general:

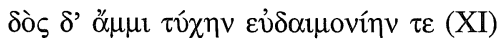

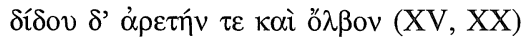

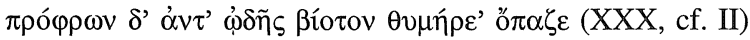

¿ $\lambda \eta \theta^{\prime}$ 'seguido de teónimo y o atributo (I, XX, XXIII)

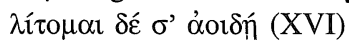

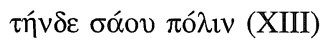

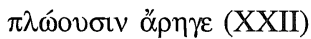

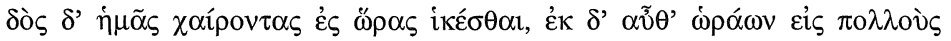

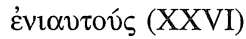

Por último se suele expresar el deseo de agradar al dios, bien mediante una promesa:

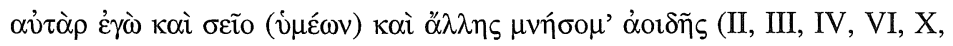
XIX, XXV, XXVII, XXVIII, XXIX, XXX, XXXIII)

o mediante la insistencia en el lugar prominente que el dedicante concede al dios.

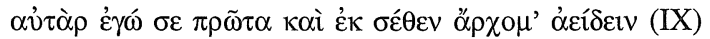

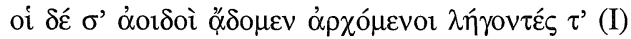

Cf. el himno XXI y el XXIV en que aparece la misma expresión de cantar al dios el primero y el último, aunque en otros lugares del himno.

Otra expresión frecuente es la del deseo de propiciar al dios con el canto

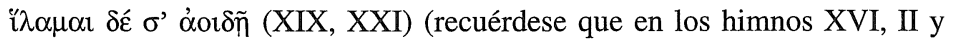
XXX el aedo ofrece el canto a cambio de la petición)

o reflejando la imposibilidad de hacer un buen canto sin recordar a la divinidad

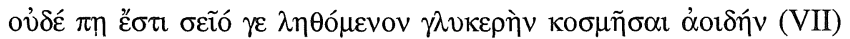

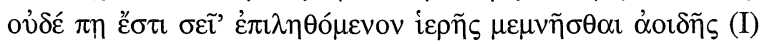

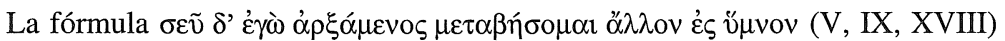
insiste en el hecho de haber comenzado por la divinidad (idea que retoma la de muchas introducciones) a la vez que indica que se va a ejecutar otro canto. Ésta es la fórmula que más claramente expresa la función del himno como proemio.

El himno XII no tiene conclusión; cabe pensar que esté incompleto. Así como la petición o el deseo de agradar al dios pueden faltar, es muy rara la omisión del saludo, lo que favorece la teoría de que $\chi \alpha \tilde{i} \rho \varepsilon$ expresa el deseo de agradar a la vez que el saludo.

\section{Comparación con otros testimonios}

\section{La plegaria cultual}

El análisis realizado revela una gran similitud entre los himnos homéricos y los himnos cultuales que se nos han conservado. Éstos son plegarias cantadas 
por la comunidad o por un coro durante actos cultuales, que solían entonarse en torno al altar, o durante el camino hacia el templo. A veces se inscribían en el mismo templo. Aparte de restos de plegarias en obras literarias, por ejemplo en el drama, se nos conservan algunos himnos, sobre todo peanes fechados a partir del s. IV a.C., en el que comenzaron a registrarse por escrito en los templos. Dado el carácter tradicional de estas piezas, la fecha de las conservadas no es óbice para utilizarlas como testimonio de los cantos cultuales de época arcaica en su comparación con los himnos homéricos.

En un estudio sobre los himnos cultuales, J.M. Bremer ha analizado estas plegarias distinguiendo tres partes: una invocación a la divinidad, una segunda parte que llama argumento, en la que se señalan una serie de características y atributos del dios que sirven para justificar la petición y que suelen ser del tipo da quia dedi, da ut dem, da quia dedisti, da quia hoc dare tuum est, y la petición, que suele referirse al bien de la comunidad ${ }^{5}$.

La invocación al dios en segunda persona aparece en los himnos XXI a Apolo y XXIV y XXIX a Hestia, y el comienzo más frecuente de los himnos,

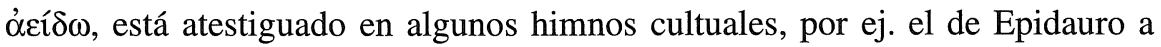
Pan ( $P M G$ 936). En el peán de Eritras (PMG 934) aparece este verbo, aunque

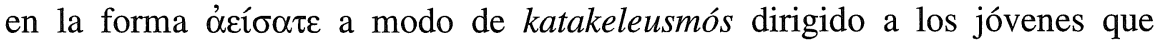

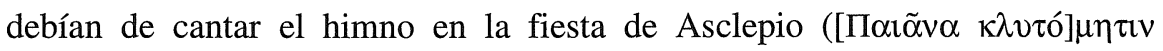

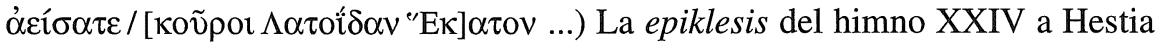

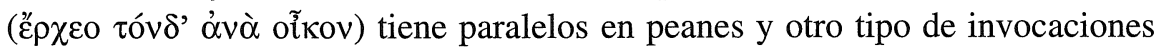

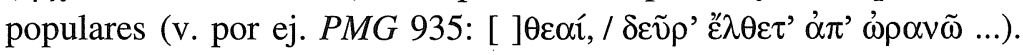

La petición ocupa en los himnos cultuales un lugar relevante, y el argumento suele estar en función de la misma, haciendo referencia a los atributos del dios que la justifican. Este es el caso también del himno XXII a Poseidón, en que la parte central viene condicionada por la petición de salvar a los navegantes, y equivaldría al tipo da quia hoc dare tuum est. Lo mismo se puede decir de otros himnos cuya parte central se refiere a la relación de los dioses con los mortales. En el himno X a Afrodita se describe su naturaleza deseable y se le pide un canto igualmente deseable; en el himno XI a Atenea se acentúa su carácter protector de ciudades y ejércitos y se le solicita suerte y felicidad. Una petición especialmente frecuente en las plegarias es la protección de la ciudad,

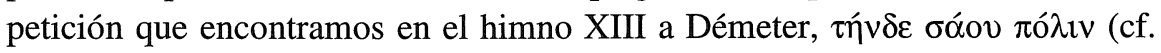

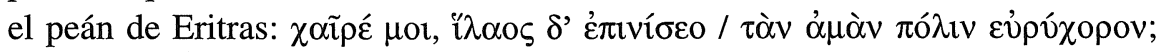

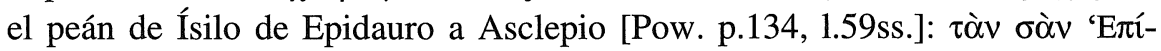

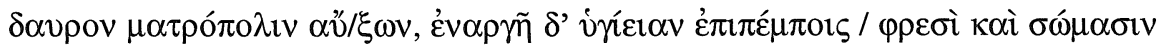

5 J.M. Bremer, «Greek hymns», en H. S. Versnel (ed.), Faith, Hope and Worship, Leiden, 1981, pp. 193-216, esp. p. 196s. 


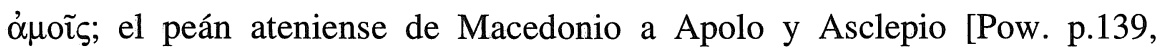

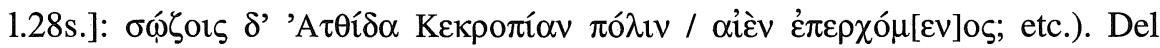
mismo tipo se pueden considerar peticiones generales en plural (es decir, referidas a una comunidad), como las de los himnos XI a Atenea o XXVI a Dioniso, y aunque no como petición, el carácter del dios como protector de la ciudad aparece en la introducción del himno XI a Atenea y en la conclusión del X a Afrodita.

Las fórmulas conclusivas que insisten en el deseo de agradar y propiciar al dios tienen su importancia como un elemento más del tipo do ut des para conseguir el favor divino. A este argumento do ut des, aunque en la conclusión

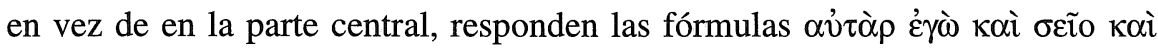

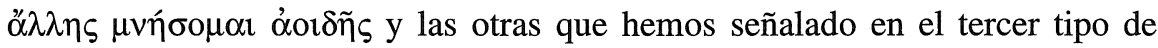
fórmulas concluyentes. Estas fórmulas concluyentes se explican pues como ofrendas a la divinidad para que ésta a su vez conceda un bello canto o, más frecuentemente, bienes de tipo más general.

Como ha señalado W.D. Furley, la referencia mítica en las plegarias cultuales establece la eficacia del ritual ${ }^{6}$. De una forma semejante la parte central de los himnos desarrolla más o menos las aretai o una narración mítica del dios, para propiciarle y hacer más eficaz la ofrenda, y aumentar con ello las posibilidades de conseguir el deseo pedido. Las referencias frecuentes en los himnos homéricos al nacimiento del dios las encontramos en los peanes de Eritras y de Ísilo de Epidauro. El himno cultual a Pan (PMG 936) es de tipo atributivo y contiene además el tópico de la llegada al Olimpo. El motivo de la consecución de las timaí por un dios aparece en el himno cultual de Epidauro a la madre de los dioses ( $P M G$ 935) que tiene reminiscencias del himno homérico largo a Démeter. Más tarde veremos cómo los himnos y las plegarias cultuales parecen beber de una misma tradición teogónica.

Podemos concluir pues que los himnos homéricos, al menos los cortos, son plegarias. Estas plegarias tienen sin embargo una característica especial, aparte de la métrica en hexámetros, que es la afirmación, frecuente en la introducción y a menudo repetida en la conclusión (I, V, IX, XVIII), de que el himno es

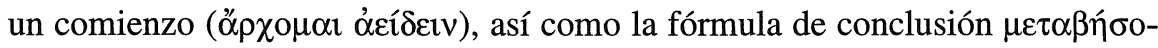

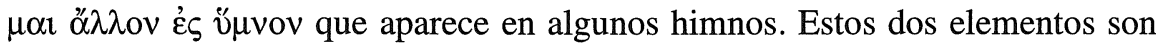
los que hacen pensar que la función de estas plegarias era la de servir de proemios, aunque no es necesario extender dicha función a los casos en que no aparecen dichas fórmulas. Recapitulando sobre lo dicho, se perfila ya la función de, al menos, parte de los himnos homéricos: iniciar algo por medio de una plegaria (otros pueden ser simples plegarias). Será necesario precisar

6 W.D. Furley, «Praise and Persuasion in Greek Hymns», JHS 115, 1995, pp. 40-46. 
más examinando los contenidos de la plegaria. De momento, pasamos a analizar los proemios que conocemos de época arcaica.

\section{Los proemios arcaicos}

Tenemos algunos fragmentos que demuestran la existencia de invocaciones a los dioses cantadas por un solista precediendo a refranes, exclamaciones y danza en un contexto festivo (procesiones religiosas, trenos y otras manifestaciones líricas). Fuentes secundarias hacen alusión al solo que se canta o toca a modo de proemio, por ej. Píndaro, en la Pítica primera (1ss.) dice de la forminge que los cantores obedecen a sus pautas cuando pulsada conforma el tañer de los proemios que introducen la danza ( $\dot{\alpha} \gamma \sigma \iota \chi o ́ \rho \omega v \pi \rho o o u \mu i ́ \omega v)$. Ésta debía de ser la función de epikleseis como la dirigida a Dioniso (PMG 871:

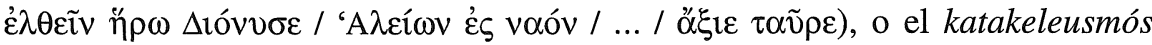
que hace el daidouchos para que se invoque a este mismo dios en los agones

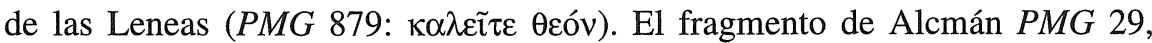

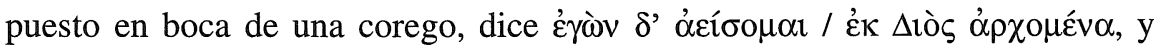
los fragmentos 76 y 77 (D) de Arquíloco atestiguan el término $\varepsilon$ $\xi \alpha \rho \chi \varepsilon ́ \omega$ para

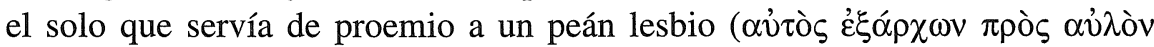

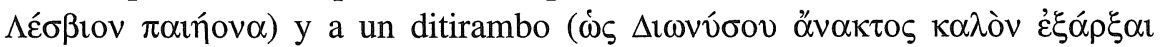

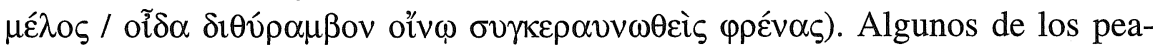
nes tenían sin duda la función de comenzar la celebración ritual, como demuestra el hecho de que muchos se cantaran camino del templo. Un ejemplo

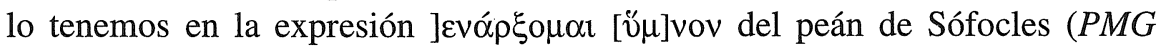
737).

A estos testimonios pueden añadirse los que da A. Aloni como ejemplos de proemios dactílicos a ejecuciones corales: Alcmán PMG 162 (proemio, muy mal conservado, probablemente a un partenio) y el himno a Démeter, Core y Climeno de Laso de Hermione, transmitido por Ateneo (XIV 624 e-f: $\Delta \alpha ́ \mu \alpha \tau \rho \alpha$

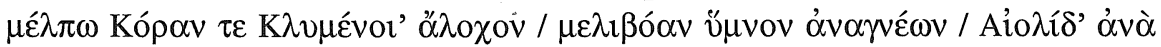
$\beta \alpha \rho v ́ \beta \rho o \mu$ ov $\alpha \rho \mu o v i ́ \alpha v){ }^{7}$. Este autor aduce estos paralelos como argumento para su convincente teoría de que el himno largo a Apolo era un proemio no a cantos rapsódicos, sino a composiciones líricas corales (las propias de la fiesta de Delos, a las que se alude en el himno), y afirma que el proemio épico debió de ser una praxis consolidada en relación con las ejecuciones más antiguas de ditirambos. Sus propios paralelos y los demás testimonios presentados

7 A. Aloni, «La performance di Cineto», en R. Pretagostini (ed.), Tradizione e innovazione nella cultura greca da Omero all'età ellenistica, Roma, 1993, p. 139s. Este autor menciona además la referencia de la Suda, según la cual Arión compuso ớ $\sigma \mu \alpha \tau \alpha \pi \rho o o i ́ \mu 1 \alpha$

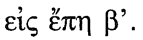


hasta aquí hacen que por lo menos dudemos de la clasificación de «épicos» para los himnos cortos, tanto si tienen claramente función de proemio como si no.

Por otro lado el tratado de Musica del Psd. Plutarco nos dice (4=1132D)

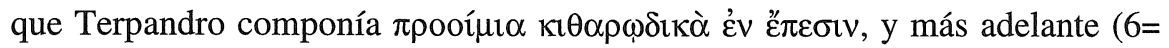
1133C) que los antiguos citarodos pasaban enseguida a los poemas de Homero y de otros una vez que habían hecho las dedicaciones a los dioses como querían, y que eso resulta evidente por los proemios de Terpandro ( $\tau \grave{\alpha} \pi \rho \grave{\varsigma}$

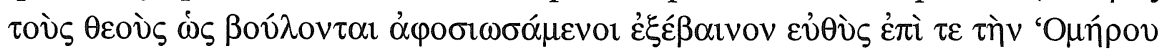

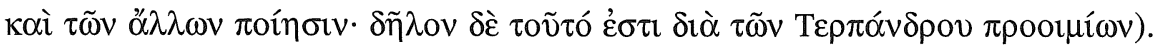
West, interpretando los himnos homéricos como proemios rapsódicos, afirma que podemos decir de los rapsodos lo mismo que el psd. Plutarco dice de los citarodos, y que debía de existir una serie de proemios citaródicos comparables a los rapsódicos, con fórmulas de transición para colocarlos delante de cantos épicos, que colectivamente se atribuían a Terpandro ${ }^{8}$. A un proemio de este tipo debían de pertenecer los fragmentos atribuidos a este autor $P M G$ 698:

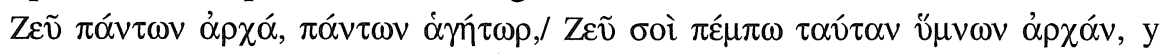

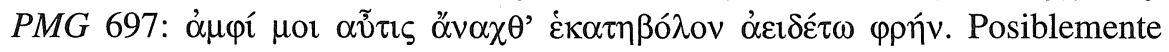
también pertenezcan a un proemio (quizá a la transición en la conclusión) los versos que se tomaron como prueba de que Terpandro aumentó las cuer-

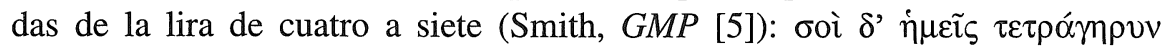

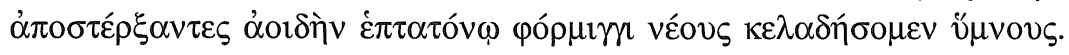

Los proemios de Terpandro PMG 698 y 697 no son ciertamente hexamétricos (a pesar de la afirmación ya mencionada de que componía proemios $\dot{\varepsilon} v$

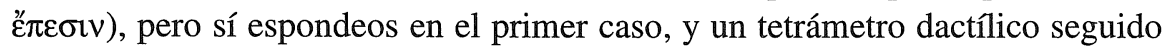
de yambos en el segundo. H. Koller, en un estudio sobre el proemio citaródico recoge como testimonios de este tipo de proemios, aparte de estos versos de Terpandro, otros hexamétricos o con otros ritmos dactílicos, a veces cerrados por un verso más corto en otro tipo de métrica ${ }^{9}$. Este es el caso de Alcmán PMG 27 (tetrámetros dactílicos), del proemio que recoge Wilamowitz (Timotheos. Die Perser, Leipzig 1903, p. 97: dos hexámetros con cláusula trocaica), del comienzo de los Persas de Timoteo (a juzgar por el primer verso conservado, en hexámetros); del proemio transmitido por Stobeus Ecl. (I, I 31: nueve hexámetros seguidos de un verso más corto). El autor menciona además una cosmogonía citaródica que comienza en hexámetros y que aparece en Eurípi-

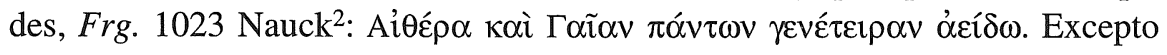

8 M.L. West, «Stesichorus», CQ 21, 1971, p. 307.

9 H. Koller, «Das kitharodische Prooimion», Philologus 100, 1956, pp. 170-4. 
en el caso de Timoteo, los demás proemios contienen una invocación a una o varias divinidades.

Creo que las fuentes secundarias sobre proemios hímnicos arcaicos y, sobre todo, las huellas aisladas en la lírica cultual popular que tienen numerosos elementos comunes con los himnos y que, posiblemente por tener aspectos formales diferentes, no han sido puestas en relación con éstos, son fundamentales para entender la función de estas piezas sin dejarse condicionar por la clasificación alejandrina que las ha agrupado. Pero tenemos además obras literarias con una parte inicial que claramente cumplía la función de proemio hímnico.

En primer lugar tenemos el proemio a la Teogonía de Hesíodo. Desde el artículo de Friedländer de 1914 se suele aceptar la unidad y autenticidad de los primeros 114 versos de esta obra como proemio, frente a las divisiones y recortes llevados a cabo por los filólogos decimonónicos ${ }^{10}$. Este proemio, que por su contenido es claramente un himno (a las Musas), tiene una serie de elementos que reencontramos en los himnos homéricos. En realidad, podemos ver con Minton un doble proemio formado mediante un proemio de tipo descriptivo-narrativo (vv. 1-36) y otro de tipo teogónico (vv. 36-79), que tienen una última parte común (80-114) en la que se describen las timai del dios y se concluye ${ }^{11}$. En los dos comienzos encontramos la fórmula «comencemos nuestro canto por las Musas», seguido de un relativo «que habitan...»/ «que a Zeus padre alegran...». El primero continúa describiendo una actuación corriente de su vida, cómo danzan en el Helicón y cómo marchan cantando himnos a los dioses. La parte central del segundo consiste en una escena semejante a la anterior, pero en el Olimpo (motivo recurrente en los himnos), y una narración teogónica que termina con la marcha de las musas al Olimpo (motivo típico) y una lista de sus nombres a modo de catálogo, que recuerda a la lista de epítetos divinos con que terminan algunos himnos. Como final, el primer proemio tiene un relato de la consagración de Hesíodo como cantor (cf. la sphragis en el himno a Apolo), y, por último, el encargo de alabar con himnos a los dioses y cantarles siempre a ellas, al principio y al final, utilizando así una fórmula típica de las conclusiones de los himnos homéricos. El segundo proemio pasa directamente a la parte que Minton ha señalado como conclusión a ambos proemios, los versos 80-103, que encierran las timai, es decir las prerrogativas y beneficios de estas diosas en relación con los hom-

10 P. Friedländer, «Das Proömium von Hesiods Theogonie», Hermes 49, 1914, pp. $1-16$.

11 W.W. Minton, «The proem-hymn of Hesiod's Theogony», TAPA 101, 1970, pp. 357-77. 
bres, elemento que no suele faltar en los himnos largos y que constituye el núcleo central de muchos de los himnos cortos, como ya hemos visto en el análisis interno. Los versos finales 104-115, que Minton define como un segmento concluyente extremadamente inusual, creo que pueden considerarse como una fusión de una conclusión hímnica típica formada por un saludo y

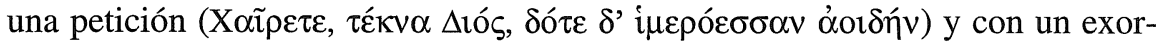
dio épico típico también, que recuerda a los exordios de la Ilíada y Odisea. En este exordio el poeta le pide a las diosas que le digan cómo nacieron los dioses, cómo se repartieron las riquezas y cómo se dividieron los honores, aspectos que corresponden precisamente a los que suelen tratar los himnos largos. La

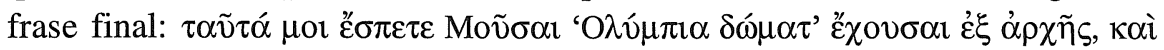

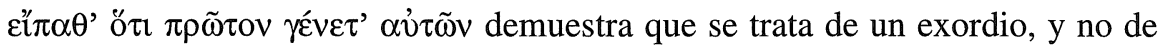
un proemio. En éstos últimos, el aedo dice que habiendo empezado por el himno a la divinidad seguirá por otro, o que se acordará del dios y de un nuevo canto en un futuro, o que se le canta al principio y al final, como aparece en el v. 35 de la Teogonía, que sí es una conclusión proemiática hímnica.

Pero hay otros textos que sin duda son proemios arcaicos, y que también deben de ser analizados en relación con los himnos a pesar de no ser composiciones hexamétricas.

Por fuentes indirectas sabemos que los cantos y recitaciones que acompañaban a la bebida después de la comida en los banquetes eran precedidos de un himno a los dioses. Platón dice en el Symposion (176a): $\sigma \pi \circ v \delta \alpha ́ \varsigma \tau \tau ~ \sigma \varphi \tilde{\alpha} \varsigma$

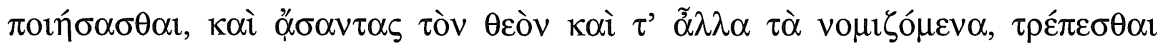

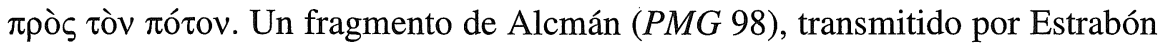

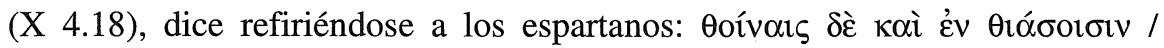

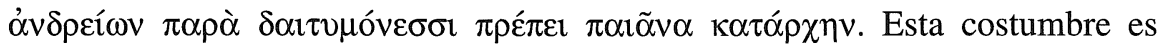
seguramente la que llevó a que se nos transmitiera la colección de elegías de Teognis, sin duda simposíacas, así como la colección de escolios, transmitidos por Ateneo (XV 694c ss.), con los himnos al comienzo.

La colección teognídea comienza con tres himnos:

El primero, a Apolo (vv. 1-10), se inicia con una invocación ( ${ }^{\tau} \Omega$ ờv $\alpha, \Lambda \eta \tau o \tilde{v} \varsigma$

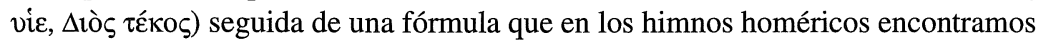

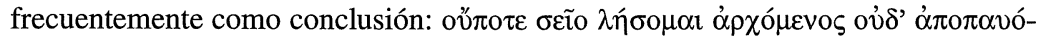

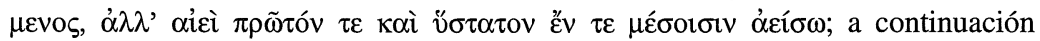

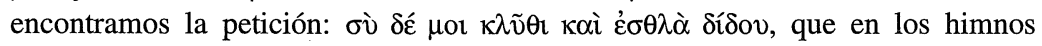
homéricos también forma parte de la conclusión, y por último la parte mítica (parte central en los homéricos), iniciada por un vocativo Фої $\beta \varepsilon$, que abre tres himnos homéricos. Esta parte central rememora el nacimiento de Apolo en Delos con claras reminiscencias del himno a Apolo (vv. 115-18).

El segundo himno es una plegaria a Ártemis (vv. 11-14) con una invocación inicial en vocativo con epíteto, una parte central atributiva (sobre el templo que 
le fundó Agamenón) introducida por un relativo, y una conclusión a modo de

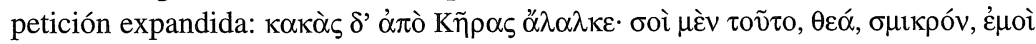

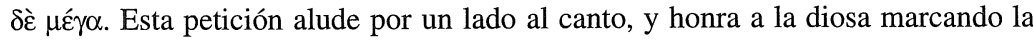
diferencia entre ella y los mortales, utilizando así, de una forma original, un tópico que encontramos en los himnos.

El tercer himno (15-18) es una invocación a las musas, con un vocativo con epíteto seguido de un relativo de transición a la parte central. Ésta es la narración de un episodio de la vida de las Musas, que alude a su carácter de cantoras, y que termina con unas palabras de tipo gnómico en boca de estas diosas, que hacen alusión indirecta al canto, sustituyendo así la conclusión que falta en este himno. El final de la parte mítica o atributiva consistente en palabras del dios aparece en algunos himnos homéricos (el III a Apolo, el VII a Dioniso). Como paso intermedio entre estos tres himnos y el comienzo de los consejos morales a Cirno el autor recurre a una sphragis, elemento que encontramos en el proemio de la

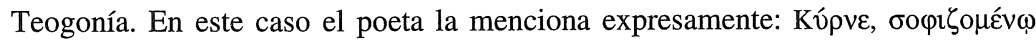

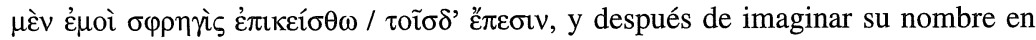
boca de todos y su fama en todas las naciones (cf. el himno largo a Apolo), se compara con Zeus justificándose por no poder agradar a todos.

En la colección de escolios, probablemente del s. V pero con material más antiguo, que nos transmite Ateneo (694C ss.) tenemos cuatro himnos que de forma sin duda no casual aparecen al comienzo. Seguramente el simposiarca abría el banquete con ellos.

El primero ( $P M G$ 884) es una invocación a Atenea suplicándole por el bien de la ciudad (súplica que hemos visto en las plegarias cultuales y en algunos himnos).

También en vocativo se dirige el poeta a Pan en el cuarto himno ( $P M G$ 887). Una serie de atributos corresponden en este caso a la parte central, y el deseo de agradar al dios con el canto forma la conclusión.

El tercer himno ( $P M G$ 886) corresponde a la parte central de una plegaria, referida al nacimiento de Febo y Ártemis. Es posible que se trate de una plegaria

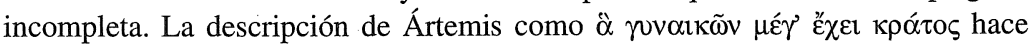
referencia a una de sus timai.

En el segundo himno ( $P M G$ 885) tenemos la misma estructura que en los homéricos pero sin parte central. El poeta invoca en primera persona a la diosa mediante el verbo óćí $\delta \omega$ precedido de un atributo y seguido del nombre de la diosa Démeter en acusativo. Este comienzo se expande de una forma original, señalando el momento de la invocación «en la estación que trae las coronas», lo que tratándose de Démeter puede equipararse a los atributos que siguen al nombre del dios invocado en otros casos. Una nueva expansión añade la plegaria a Perséfone. A continuación la conclusión consta del saludo y la petición de protección a la ciudad que ya hemos visto en plegarias cultuales, himnos homéricos y en el proemio de Teognis. La estructura y el contenido de este himno son idénticos al himno homérico XIII dedicado a las mismas diosas.

$P M G 885$

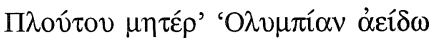

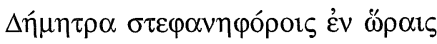




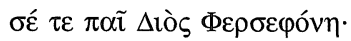

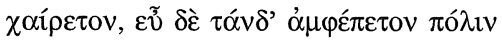

Himno homérico a Démeter (Càssola h.Hom. 13),

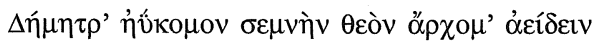

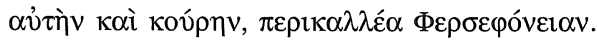

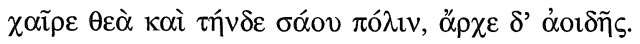

Así pues, una función básica de la plegaria era la de proemio a actos diversos: celebraciones cultuales, banquetes, reuniones, agones. Dicho de otra forma, era frecuente comenzar cualquier ceremonia cultual y muchos tipos de ceremonias sociales por una invocación a la divinidad con el fin de agradarla y conseguir su favor, y creo que no es exacta la afirmación de M.P. Nilsson, de que los sacrificios cumplían entre los griegos la misma función que los rezos propiciatorios de nuestra sociedad ${ }^{12}$. También los griegos «rezaban». A esta costumbre de comenzar cualquier actuación con una plegaria a la divinidad responden, aparte de los proemios mencionados, los abundantes ejemplos que encontramos en la lírica arcaica de introducciones con elementos hímnicos (por ej. en Píndaro, $\mathrm{Ol}$. 2, 4; $\mathrm{Pi} .1,6,7 ; \mathrm{Ne} .2,3,4,9$ ). Resulta muy significativa en este sentido la costumbre de los alejandrinos de poner al frente de las ediciones las composiciones de tipo hímnico. Éste es el caso por ejemplo del himno a Afrodita de Safo, que era el primer poema del primer libro en la edición alejandrina, o de la plegaria de Anacreonte ( $P M G$ 348), a la que el

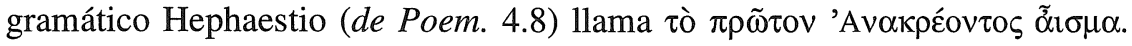

\section{Fuentes secundarias}

Veamos ahora qué información proporcionan las fuentes antiguas sobre el carácter de los himnos homéricos. Tucídides (III 104), hablando de las fiestas de Delos, atribuye a Homero unos versos del himno a Apolo diciendo que son

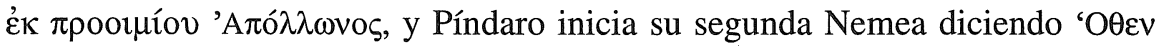

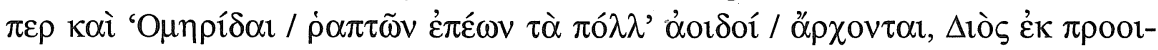

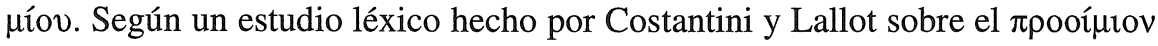
parece que su sentido más antiguo es el de himno preliminar, a juzgar por las

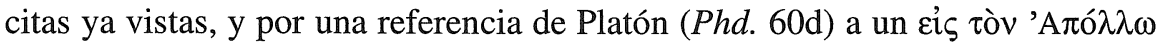

12 M.P. Nilsson, Greek Folk Religion, Philadelphia, 1972 (= Greek Popular Religion, N. York, 1940), p. 73: "Whereas we say a prayer before and after the meal, the Greeks before the meal offered a few bits of food on the hearth and after it poured out a few drops of unmixed wine on the floor». Cf. en cambio, W. Burkert, Greek Religion, Cambridge Mass. (= Griechische Religion der archaischen und klassischen Epoche, Stuttgart, 1977), pp. 73-5. 
$\pi$ pooífutov que escribe Sócrates ${ }^{13}$. Muy pronto adquiere el sentido de exordio a las leyes, y a partir del s. V se usa principalmente en la oratoria para el preámbulo de un discurso, y por extensión para cualquier comienzo. Así se explica que, cuando el término empezó a generalizarse, se optara por el de v̋ $\mu$ vo para los himnos homéricos. A partir del s. III todas las menciones a himnos homéricos utilizan la palabra ü $\mu v o \varsigma$, que en época helenística se refería exclusivamente a un canto dedicado a un dios: D.S. I 15.7; III 66.3; IV 2.4 (h. Dion.); Ph., de Pietate (Gompertz, p. 42); Paus. IV 30.4 (ref. al h. Dem.); X 37.5 (h. Ap.); Ath. 22b (h. Ap.). En la época arcaica sin embargo tenía el sentido muy genérico de 'canto'. Así se deduce de pasajes como Od. VIII 429, Alcmán PMG 27, Safo 44.34 (Voigt), Esquilo, Ag. 709, o los numerosos usos de Píndaro, en los que se refiere a cantos a mortales (Ol. I 8, $N$. VIII 50, etc.).

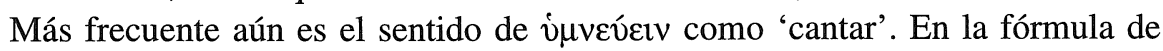

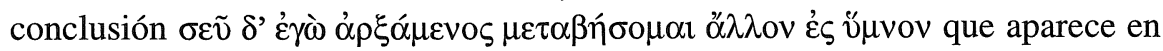
algunos himnos, el aedo dice que pasará a otro canto, que no tiene que estar necesariamente dedicado a una divinidad, ni ser necesariamente épico. En época clásica sin embargo, el término debió de ir especializándose para designar

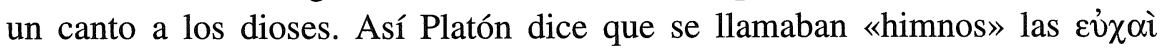

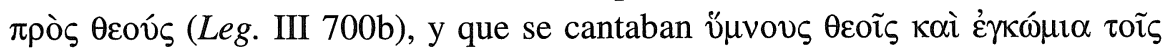
$\dot{\alpha} \gamma \alpha \theta$ oĩs (Re. X 607a).

Las alusiones en fuentes secundarias a los himnos homéricos no son de gran ayuda para determinar su función. Si bien atestiguan la función de proemio, en la única referencia a un himno concreto en que aparece el término 'proemio' (la de Tucídides), se citan versos de un himno largo, y es precisamente en éstos donde la función de proemio parece más discutible.

\section{Ocasión y obras a las que seguían los himnos}

Si estamos en lo cierto al afirmar que al menos los himnos cortos eran plegarias, cantadas en muchos casos a modo de proemios, queda ver a qué tipo de cantos o acciones antecedían, y con ello, en qué ocasiones se ejecutaban.

Algunos parece claro que eran proemios a cantos porque el aedo hace referencia al que va a ejecutar a continuación con la fórmula «pasaré a otro canto», o, en el caso del himno XIII a Démeter «da principio a mi canto». Los agones rapsódicos están bien atestiguados y durante bastante tiempo, y la teoría más aceptada es que los himnos eran proemios en este tipo de agones. La conclu-

13 M. Costantini- J. Lallot, «Le $\pi$ pooífıv est-il un proème?», en M. Costantini et alii (er.d.), Le texte et ses représentations, París, 1987, pp. 13-27. 
sión del himno VI a Afrodita: «concédeme la victoria en este agón» parece apoyar esta teoría. Sin embargo no todos los himnos tienen que ser proemios a un mismo tipo de canto, ni siquiera a un canto, ni en una misma ocasión. De hecho, la mayor parte de los himnos cortos no hacen alusión a un canto posterior, y pueden tener funciones diferentes. El himno XI a Atenea puede ser una plegaria para cantar justo antes de una acción guerrera, el XXII a Poseidón una plegaria marinera, como quizá también el XXXIII a los Dioscu-

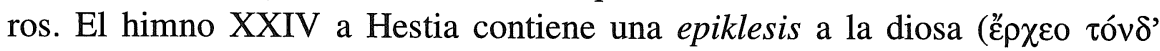
óvò oũcov), que puede interpretarse como llamada, más que al templo, como suele creerse, a una casa privada donde se está celebrando un banquete. Ya hemos visto que los cantos de banquete se iniciaban con una plegaria, pero

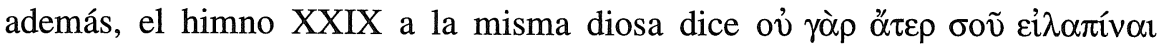

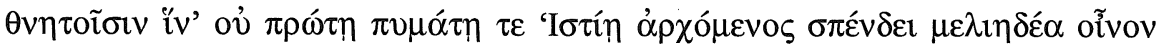
(«no hay banquetes sin tí entre los mortales, en los que el que les da inicio no haga una libación de vino dulce como la miel a tí Hestia, en primer y último lugar»). También este himno puede servir de proemio en un banquete. El

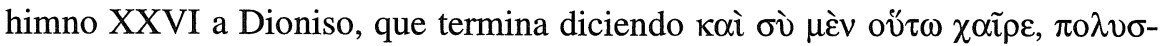

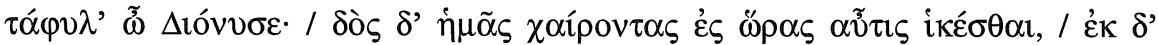

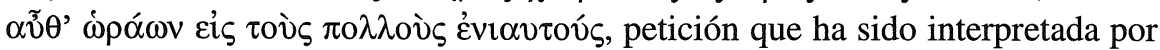
algunos autores como deseo de volver al año siguiente al agón rapsódico ${ }^{14}$, puede ser un proemio a una danza u otro tipo de celebración en una fiesta agrícola, como sabemos que se realizaban en honor de este dios. La misma interpretación puede darse a algunos de los himnos en que la petición es de carácter general, como el XIII a Démeter.

Creo que nuestro estudio demuestra que los himnos homéricos cortos pueden agruparse con varios otros testimonios de la lírica arcaica dentro de un mismo género, dada la similitud en contenido y función. Pero conviene no pasar al extremo contrario y quitar toda importancia a los aspectos formales. Se trata de himnos hexamétricos compuestos dentro de una tradición hexamétrica (como han demostrado todos los estudios sobre lengua y dicción formular, cf. Brillante -Cantilena - Pavese [edd.], Janko, Richardson) ${ }^{15}$, y obra de profesionales contratados. Es decir, aunque cumplan funciones genéricas que se pueden realizar también con otro tipo de medios, son en principio indicio de creación importante en que se requiere un profesional (cf. el repertorio de

\footnotetext{
14 A. Aloni, ob. cit., p. 135.

15 C. Brillante- M. Cantilena- C.O. Pavese (edd.), I poemi rapsodici non omerici e la tradizione orale. Atti del Convegno di Venezia (set. 1977), Padua, 1981; R. Janko, Homer, Hesiod and the Hymns: Diachronic development in epic diction, Cambridge, 1982; N.J. Richardson, The homeric hymn to Demeter, Oxford, 1974.
} 
tópicos estudiados por C.A. Sowa y C.O. Pavese) ${ }^{16}$. Esta elaboración dentro de una tradición oral profesional ayuda a aclarar la relación entre los himnos breves y los largos. En la tradición oral es básico el concepto de expansión; el aedo puede dar versiones mínimas o expandidas de un mismo tópico o tema, según las necesidades de la ocasión o la respuesta del público. Los himnos largos representan una versión expandida de un núcleo mínimo. Su origen está sin duda en plegarias, algunas con función de proemios (lo que explica la calificación de Tucídides del himno de Apolo como proemio) del tipo visible en himnos breves, pero que se han desarrollado cuando la ocasión justifica un canto autónomo y del que se pueda disfrutar por sí mismo.

Desde el punto de vista teogónico, estos himnos se entienden dentro de una tradición que pretende reconstruir el nacimiento y la llegada al Olimpo de los dioses por un lado, y la adquisición de las timai y su relación con los mortales por otro. Estos distintos motivos son recurrentes en los himnos largos, pero también en los cortos, que con seguridad toman su contenido de la misma fuente. Así se explican analogías de versos enteros entre el himno corto a Hermes y el largo al mismo dios, o entre los versos 2-5 del himno XXV a Apolo y las Musas y los versos 94-7 de la Teogonía, por citar sólo dos ejemplos. Los motivos del dios que se separa durante un tiempo del Olimpo, del joven dios que consolida su poder, del dios inventor que enseña su ciencia a los mortales, por ej. en el himno a Hermes o el XX a Héfesto, de la seducción, o del viaje del dios, motivos centrales de los himnos, han sido estudiados por C.A. Sowa dentro de una larga tradición ${ }^{17}$. La mayor insistencia en uno u otro de estos motivos en cada himno se debe probablemente al contexto en que se ejecutaba la composición. En muchos himnos cortos que son claramente plegarias el motivo fundamental es el de la relación del dios con los mortales, en los himnos a Apolo y Démeter el motivo fundamental es la descripción de los momentos de la vida del dios que se repiten en el ritual. Todos los himnos

16 C.A. Sowa, Traditional themes and the Homeric Hymns, Chicago, 1984; C.O. Pavese, «I poemi epici rapsodici come poemi orali e independenti», Atene e Roma 40.1, 1995, pp. 1-21.

17 C.A. Sowa, ob. cit. Cf. las teorías actuales que explican los himnos largos como piezas que llenan la laguna existente entre la teogonía hesiódica y la reconstrucción religiosa de Homero. Según éstas (J. Rudhardt, «A propos de l'hymne homérique à Déméter», $M H$ 35, 1978, pp. 1-17; ibid., «L'hymne homérique à Aphrodite. Essai d' interpretation», $M H$ 48, 1991, pp. 8-20; J.S. Clay, The politics of Olympus. Form and meaning in the major homeric Hymns, Princeton, 1989) los himnos largos no pretenden explicar ninguna leyenda local ni están adscritos a ninguna fiesta o celebración religiosa concreta. Su panhelenismo está destinado a reflejar cómo Zeus se hizo con el poder absoluto en el Olimpo eliminando a posibles sucesores o riesgos (en los himnos a Afrodita y Démeter), y cómo iba concediendo sus prerrogativas a nuevos dioses (himnos a Hermes y Apolo). 
adaptan a su contexto uno o varios motivos de una tradición teogónica sin duda larga y compleja como revela la Teogonía hesiódica y las frecuentes alusiones en obras diversas a que la Musa cantaba las hazañas de los héroes y también las de los dioses.

Sin embargo, esos motivos teogónicos no parecen exclusivos de una tradición épica (la mayor parte son ajenos a Homero), y los encontramos en las plegarias cultuales y populares mencionadas, y también en diversas manifestaciones de la lírica arcaica ${ }^{18}$. Ya hemos visto los temas típicos del nacimiento del dios, su acceso al Olimpo, su relación con los mortales. Incluso motivos mucho más complejos se repiten en las plegarias y los himnos homéricos. Así, el del enfado de Démeter con los dioses y su negativa a volver al Olimpo, que encontramos en el himno largo a Démeter, hasta que no le concedan sus timai es el tema central del himno a la madre de los dioses ( $P M G$ 935).

Los llamados himnos homéricos forman pues una colección de himnos muy dispares en longitud, divinidades invocadas y función, que fueron agrupados por los alejandrinos siguiendo un criterio meramente formal: su composición hexamétrica y su carácter formulario, que fue por otra parte el que motivó su atribución a Homero.

El problema que envuelve la cuestión del género al que pertenecen los himnos radica, en parte, en que para los antiguos, antes de la crítica alejandrina, la literatura se definía sobre todo por su función en un contexto social determinado. Los alejandrinos sin embargo dan prioridad a aspectos formales (metro, etc.), tanto por razones literarias en relación con su propia poética, como por la razón práctica de que tenían que editar obras cuya función social se había perdido en gran parte ${ }^{19}$. Esta tradición alejandrina ha condicionado muchos de los estudios modernos, dificultando la clasificación de los géneros arcaicos. C.O. Pavese por ejemplo define los géneros basándose en tres factores: ejecución, métrica y lengua, mediante los que distingue entre rapsodia, citarodia y lírica, y afirma que se diferencian en especies según el contenido ${ }^{20}$. Así, divide la rapsodia en heroica (de entretenimiento) y en didascálica, en la que incluye la teológica con los himnos homéricos. Pero ciertamente parece que la función, y con ella el contenido, era más significativa para los griegos

18 Cf. los himnos de algunas odas de Píndaro, como por ejemplo el de Hermes en el segunda Nemea, en que aparece el motivo del acceso del dios al Olimpo como recompensa a sus muchas fatigas.

19 v. A.E. Harvey, «The Classification of Greek Lyric Poetry», The Classical Quaterly 5, 1955, pp. 157-75.

20 C.O. Pavese, «I poemi epici rapsodici come poemi orali e independenti», Atene $e$ Roma 40.1, 1995, pp. 1 y 17. Para el problema de la influencia de la clasificación alejandrina en los estudios modernos v. A.E. Harvey, ob. cit., p. 157. 
arcaicos que los aspectos formales, y creo que es fundamental esta perspectiva en el estudio de los himnos homéricos.

Ciertamente, si prescindimos de la agrupación alejandrina y después de analizar los himnos internamente los comparamos con otras composiciones arcaicas, llegamos a la siguiente conclusión: los himnos homéricos están formados en parte por elementos de una tradición épica, pero tienen otros muchos claramente líricos ${ }^{21}$. Los paralelismos de los himnos cortos con otros testimonios líricos, ya sean cultuales o festivos populares, revelan que son plegarias que en muchos casos funcionaban como proemios propiciatorios a diferentes acontecimientos (fiestas populares, agones, ceremonias cultuales, banquetes, etc.), y que la única diferencia importante respecto a las otras plegarias mencionadas es su composición en hexámetros y su carácter formulario ${ }^{22}$. Nuestra interpretación se ve además apoyada por el tipo de divinidades celebradas, que no son los dioses de la épica teogónica hesiódica, sino los dioses de culto de los griegos, dioses, algunos de ellos, que no juegan ningún papel ni siquiera en Homero, pero que son fundamentales en la religión popular arcaica, como Démeter y Dioniso.

La interpretación de los himnos homéricos como proemios está muy extendida y es muy antigua, pero suele ir unida a la afirmación de que se cantaban en contextos agonales. La comparación con otros testimonios arcaicos nos revela sin embargo que no todos los himnos cortos son necesariamente proemios y que, cuando lo son, no anteceden necesariamente a rapsodias en un contexto agonal. Lo que queremos destacar es por una parte su relación con las plegarias, que a menudo eran utilizadas como proemios en el mundo griego, y por otra parte la variedad de las ocasiones en que, como aquéllas, podían ejecutarse.

MARÍA PAZ DE HoZ

21 Cf. H. Koller, en su estudio citado sobre el proemio citaródico, quien llega a la conclusión de que los himnos homéricos cortos son proemios citaródicos, no rapsódicos, que se cantaban como breves monodias.

22 La composición hexamétrica de piezas no épicas no es exclusiva de estos himnos y no resulta por tanto un obstáculo para la interpretación dada. Ya hemos señalado las menciones a la composición de proemios citaródicos en hexámetros por Terpandro (aunque no puede verificarse mendiante los versos conservados), y hemos visto que aunque no siempre el hexámetro, pero si el metro dactílico en general es el más frecuente en los proemios citaródicos, aunque con otras cláusulas métricas como conclusión en algunos casos. El hexámetro es también el metro de los oráculos (cf. H. Koller, ob. cit., p. 170, quien afirma que el oráculo más antiguo, de Dodona, transmitido por Pausanias (X 12.10), podría ser

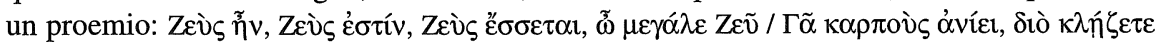

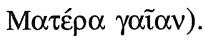

